Saint Louis University School of Law Scholarship Commons

All Faculty Scholarship

2008

\title{
The Public Face of Presumptions
}

Karen Petroski

Saint Louis University School of Law

Follow this and additional works at: https://scholarship.law.slu.edu/faculty

Part of the Legal Writing and Research Commons

Recommended Citation

Petroski, Karen. The Public Face of Presumptions. Episteme: A Journal of Social Epistemology, Volume 5, Issue 3, 2008, pp. 388-401.

This Article is brought to you for free and open access by Scholarship Commons. It has been accepted for inclusion in All Faculty Scholarship by an authorized administrator of Scholarship Commons. For more information, please contact erika.cohn@slu.edu, ingah.daviscrawford@slu.edu. 


\section{PROJECT MUSE}

\section{The Public Face of Presumptions}

Karen Petroski

Episteme: A Journal of Social Epistemology, Volume 5, Issue 3, 2008, pp. 388-401 (Article)

Published by Edinburgh University Press

$\Rightarrow$ For additional information about this article https://muse.jhu.edu/article/258360 


\title{
The Public Face of Presumptions
}

\begin{abstract}
We commonly think of presumptions as second-best inferential tools allowing us to reach conclusions, if we must, under conditions of limited information. Scholarship on the topic across the disciplines has espoused a common conception of presumptions that defines them according to their function within the decisionmaking process. This focus on the "private" face of presumptions has generated a predominantly critical and grudging view of them, perpetuated certain conceptual ambiguities, and, most important, neglected the fact that what we refer to as "presumptions" have distinguishing features other than the defeasibility and burden-shifting effects associated with their use as inferential tools. When a decisionmaker gives reasons for a conclusion, the decisionmaker often cites a presumption among the reasons for that conclusion; in this guise - their "public" face-presumptions display different, and uniquely valuable, features that remain hidden if we understand them only as aids to inference. This essay both surveys recent approaches to the critical analysis of presumptions in law, philosophy, and discourse studies, and offers an account of how we might begin to think about this other, public face of presumptions.
\end{abstract}

\section{INTRODUCTION}

Received wisdom tells us that it is less than ideal, if not downright irresponsible, to rely on presumptions. In law and logic, presumptions are tools allowing us to reach conclusions when information is limited. By definition, they are secondbest devices. Common usage treats them even less charitably. To "presume" is "to undertake without clear leave or justification." To be "presumptuous" is to act on the basis of an unjustified belief, to the shame of the presumer and the injury of those presumed against. Unsurprisingly, scholarship on the subject has focused on either limiting or defending our use of the practice and the term "presumption."

This essay argues for a reevaluation of presumptions, achieved through a shift in focus. In fact, we do not use the term "presumption" only to refer to imperfect guides to inference; we also, at least sometimes, use it to refer to a uniquely valuable form of support for a conclusion. Recent scholarly work on presumptions has focused solely on their internal or "private" face - the role they play in decisionmaking processes. This focus leads to neglect of the features 
presumptions display when they are cited among the reasons in support of an achieved decision. These features - the "public" face of presumptions - justify the persistent use of the term in argument and explanation despite apparent consensus on the questionable legitimacy of using presumptions to reach conclusions in the first place.

To justify this shift in focus, this essay describes how the private face of presumptions has been understood, and the problems this understanding has generated, in three contexts in which presumptions have been most extensively discussed: legal procedure, informal argument, and public discourse about values. The second half of the essay offers some initial suggestions regarding the function of presumptions as reasons. As it turns out, characterizing a reason as a presumption implies unique forms of commitment on the part of the reason giver-suggesting an independent value for presumptions quite different from the conventional view of them as validated, if at all, only by the absence of superior alternatives.

\section{THE PRIVATE FACE OF PRESUMPTIONS}

\section{a. The Common Conception}

All recent commentary on presumptions relies on a common conception of what the term "presumption" refers to. This conception has two components. The first is that a presumption is similar to a supposition, in that it is a proposition posited in the absence of full information, and therefore subject to defeat if further relevant information becomes available. The second component is that in dialogue or deliberation, presumptions, unlike suppositions, function to "shift the burden of proof to the opponent, or to make the opponent responsible for the proof," as Leibniz put it in 1702 ( $1702 / 1887,444$, quoted in Gaskins I992, I). Bishop Richard Whately, the nineteenth-century theologian often identified as the father of the modern study of presumptions, also emphasized this function: "[a]ccording to the most correct use of the term, a 'Presumption' in favor of any supposition, means, not ... a preponderance of antecedent probability in its favour, but, ... that the Burden of proof lies on the side of him who would dispute it." (I 828 / I 852,74$)$

These definitions imply that presumptions have a weight exceeding that of other propositions based on incomplete information - that, in deliberation or argument, presumptions might function as reasons in support of a position unless specifically overridden by subsequent information. But as explained below, the function of presumptions as reasons has not been a focus of recent approaches to the topic, which fix instead on the operation of presumptions' defeasibility and burdenshifting effects prior to the resolution of a dispute or the achievement of a decision. Comparison of these more recent approaches can help to clarify the problems resulting from this fixation. 


\section{b. Presumptions as Technical Hurdles}

It is in legal scholarship that presumptions have received the greatest attention and the greatest criticism. Their burden-shifting function is familiar to everyone acquainted with the American legal system; it is an aspect of the most basic procedural rule of the adversarial system, the rule that normally places the burden of proof on the party seeking to alter the status quo. Among countless examples of presumptions relating to more specific issues, two that are especially frequently discussed in the scholarship are the presumption that a letter was received, based on evidence that it was properly mailed (Allen \& Callen 2003, I6-24), and the presumption that a person is deceased, based on the absence of any evidence of contact with or communication from the person for seven years or more (McBaine I $938,528-9)$.

These legal rules involve the generation of special temporary "facts" effectively, legal fictions-based on other facts presented as evidence. Legal presumptions also appear in other forms, especially in constitutional and statutory interpretation. For example, judges deciding whether to apply a statute to conduct that occurred outside the territory of the sovereign enacting the statute often refer to a "presumption against extraterritorial application" in explaining whether the statute applies (American Banana i 909, 357). This presumption, and many similar tools of statutory and constitutional interpretation, are in a sense analogous to more fact-bound presumptions. Like fact-bound presumptions, interpretive presumptions involve a kind of authorized conventional inference about legislative intent, based on the "evidence" of statutory text. But because these interpretive presumptions operate outside the regime of what the law conventionally classifies as "evidence," they have not received anything like the amount of attention lavished on fact-bound presumptions.

The narrow focus on evidentiary presumptions in legal scholarship has not led to clarity. It is nearly a cliché for legal articles on this topic to begin by quoting one of any number of statements about the obscurity of the topic. Since the early twentieth century, the central issue debated has been the precise nature of the burden that a presumption places on the party opposing the presumption, and the procedural implications of the answer to this question (Thayer I 898, 339; Morgan I955). The debate over the procedural implications of evidence-based presumptions continues today.

To be sure, most of the participants in this debate have agreed on a few points beyond the core definition of presumptions presented above. But these points of agreement involve difficulties of their own. One point of consensus is that because presumptions are procedural rules governing the responsibilities of parties to a dispute, they are distinct from evidence and cannot be a source of evidence, so juries should not be instructed to weigh a presumption against any facts presented in rebuttal of it (Hecht \& Pinzler i978, 54I \& n.76; Morgan 1937, 27I , 274). Very few commentators have concluded that legal presumptions, or the 
factual propositions resulting from their operation, can and do function as evidence (Olshausen I943, 32 I , 323-34; Kaiser I 95 5, 26 I). This widely shared understanding of presumptions as housekeeping rules distinct in kind from the evidence on which they operate has probably encouraged an understanding of presumptions as devices that stand apart from, and are not comparable to, the basic reasons for a legal conclusion.

Legal commentators also widely agree that so-called "irrebuttable" or conclusive presumptions do not deserve the name. Conclusive presumptions are legal inferences that the law requires a decisionmaker to draw from given evidence, such as the traditional rule that a child below a certain age is incapable of a criminal act. The position that these are not really presumptions is directly entailed by the common conception of presumptions: conclusive presumptions are not defeasible, so they lack one of presumptions' defining features (Allen \& Callen 2003, 3 n.7; Hecht \& Pinzler I978, 529; Morgan 1937, 25 5; Olshausen I943, 3 I6). The standard position on the use of the term "presumption" to refer to legal rules of this type is that the usage results from conceptual sloppiness, a disregard for the defining features of presumptions. But decades of criticism in this vein have not made much headway against the usage itself; such rules are still regularly referred to as "presumptions." This convention might be more satisfactorily explained if we could relax the requirement that presumptions be defeasible in any given case and any context in which they are considered, a point explored below.

A final point agreed on by most commentators, and presupposed by current legal practice, is that despite these perplexities the term "presumption" remains useful. But this view has had dissenters, notably Ronald Allen, who has argued since at least I98 I that lawyers and courts should stop using the term, since "presumptions do not exist independently of other evidentiary devices and procedures that go by other names," specifically, the standards for directed verdicts and affirmative defenses (I98I, 844). Allen has shown repeatedly that the term "presumption" does not refer to anything unique as far as procedure is concerned - yet his demonstration has had no discernible effect on legal usage and practice. Perhaps this persistence is due not to inattention to Allen's analysis, but to the fact that the term has meaning beyond its reference to an evidence-marshaling inferential device.

\section{c. Presumptions as Indispensable Starting Points for Inquiry}

Philosophers who have examined presumptions have relied on the common conception described above to draw far less critical conclusions about use of the term "presumption" and the practice to which it is understood to refer. Two of the philosophers who have considered presumptions at greatest length, Douglas Walton and Nicholas Rescher, have both insisted that presumptions are not a matter of merely technical interest but instead play a fundamental role in reasoning - that we wouldn't be able to agree about anything or say that we knew 


\section{Karen Petroski}

anything at all were it not for presumptions. But because both Walton and Rescher base their analyses on the common conception, their treatments cannot resolve the ambiguities characterizing legal scholarship on presumptions. If anything, their conclusions further accentuate those ambiguities.

In a series of works on the subject of "presumptive reasoning," Walton has argued that presumptions are crucial to practical reasoning, since they are what "enable a dialogue or an action to go ahead on a provisional basis in time to be of some use in providing a tentative solution to a practical problem" (I996, xi). But Walton uses the term "presumption" in two different senses. Sometimes he uses it to refer to specific defeasible inferences drawn from a particular set of facts. One of his examples is the presumption that the husband of a person's mother is the father of that person, in the absence of reason to believe otherwise (39). Walton also, however, uses the term to refer to the operation of what he calls "presumptive reasoning," forms of inference that we conventionally consider fallacious-like slippery-slope reasoning - but that may be legitimate grounds for inference under conditions of limited information (48-ro9). In this sense, presumptions are not specific propositions but classes of provisional warrants, or perhaps the generic results of licensed structures of provisional inference. This ambiguity mirrors the ambiguity in legal usage, which uses the term "presumption" to refer both to legal rules licensing certain inferences on the basis of particular evidence and to the resulting specific conclusions (Morgan I937, 257, 278). The ambiguity is, however, more pronounced in Walton's work because the schemes he examines are even more general than the typical legal presumption. We could avoid the ambiguity by adopting different terms for each sense in which the term "presumption" gets used, of course-but it is also possible that the ambiguity derives not from carelessness but from a more basic ambiguity in the nature of presumptions, one that can be better understood by considering how they function as reasons. As explained below, a reason characterized as a presumption has features of both specific propositions and general rules, and cannot be reduced to one or the other.

A similar ambiguity is present in Nicholas Rescher's work on presumptions (2006), although it is less evident here, since Rescher focuses primarily on presumption as an identifiable phase in a ubiquitous structure of practical inference. Rescher describes presumption as a practice of "tentative cognition," and more specifically as the practice of making provisional inferences in the absence of full information; he explains how this is something we do constantly in every area of rational inquiry (52). Only derivatively does this practice solidify into rules of thumb for drawing particular inferences, which are also referred to as "presumptions." Rescher's chief concerns are to demonstrate the ubiquity of this practice and to justify it in what he calls "economic" terms. As he puts it, "presumption is a matter of cognitive economy - of the eminently rational policy of following 'the path of least resistance' to an acceptable conclusion" (47). This justification, again, applies equally to the practice in general and to particular low-cost inferential results. But it is limited to the justification of certain deliberative processes and their results, 
generically considered; it focuses on whether the use of presumptions can generally be justified, not on how they are used to justify. As a result, Rescher's defense of the practice of presumption offers no resources for resolving the conceptual problems that have arisen in other work on presumptions. It cannot, for example, explain the persistent use of the term to refer to phenomena that seem to lack the attributes of presumptions understood under the common conception.

\section{d. Presumptions as Tools for the Opportunist}

Scholars studying presumptions commonly note that the shape of presumptions in both senses - the content of both presumptive rules and the inferences licensed by them -is determined by external norms. The presumption of paternity cited by Walton, for example, seems to be based on a default assumption that people conduct themselves in conformity with dominant social norms. Dale Nance (I 994) has argued that all legal burdens of proof are best explained according to a related "principle of civility": an assumption that, absent evidence to the contrary, individuals acting voluntarily always conduct themselves consistently with relevant norms. On this account, presumptions generally presuppose and promote prosocial, cooperative behavior.

Some references to presumptions, however, are not sociability-promoting. This is particularly true in the field of public discourse about values, explored by Richard Gaskins in his 1992 book on burdens of proof in modern discourse. Gaskins is interested in the phenomenon of burden-shifting in argument, not the dynamics of defeasibility. He finds this phenomenon to be "an inescapable feature of contemporary discourse" and explains it as "a natural consequence of modern pluralism" (3). In particular, he examines the widespread reliance in policy debates on the "argument from ignorance," whereby the assertion of a principle is accompanied by an overt or implicit assertion that if interlocutors cannot invalidate the proposition asserted, it must be accepted as valid (2-I I). Among many other examples, he points to a twentieth-century shift in legal and popular discourse from a presumption of perfect rationality in the operation of bureaucracies to a presumption that bureaucracies inevitably fall short of that ideal. According to Gaskins, this shift has underwritten successive phases of constitutional due process doctrine as well as changes in public attitudes toward institutional authority (83-IOI). And in Gaskins's account, it resulted not from the operation of a principle of civility but from the opportunism of actors who used burden-shifting rhetoric to further objectives based on other commitments, including self-interest (IOI-2).

Although Gaskins is critical of this dynamic, and although his emphasis is on burden-shifting rather than defeasibility, his ultimate conclusions resemble Rescher's. Gaskins describes judges interpreting the Constitution, for example, as avoiding justification of their key assumptions by claiming the advantage of a presumption on a particular issue and shifting the labor of justification onto 
those who would dispute their conclusions (54-74). Gaskins thus comes closer than any other recent commentator to considering the function of presumptions as reasons. But for him, burden-shifting in public discourse remains a tactic for evading argumentative responsibility - a basically antisocial act. Like Rescher, he characterizes presumptions as propositions that are "taken" by arguers, not "given" to an audience. The implication is that every reference to a "presumption," and every inferential practice conforming to the common conception, bears a hint of illegitimacy.

\section{e. What the Common Conception Neglects}

The sense that there is something less than legitimate about presumptions explains why commentators have focused on defining their legal operation narrowly and on elaborately justifying the use of presumptions, and the term "presumption," outside the law. But the emphasis on justification and containment of presumptions, and the reliance on the common conception, miss something important about presumptions: the way they operate as a form of justification.

A hint of what is missing from the approaches described above appears in Bishop Whately's approach to the topic. Whately is universally cited as the originator of the modern understanding of presumptions. But Whately's discussion of presumptions appears in a handbook of argumentation. He was not concerned with justifying the use of presumptions, and this was largely because he understood them primarily as persuasive, not inferential, tools. Indeed, the core of his advice to his readers regarding presumptions was not a warning of their illegitimacy, but a reminder of their utility: "if you ... suffer[] the Presumption to be forgotten, which is in fact leaving out one of your strongest arguments, you may appear to be making a feeble attack, instead of a triumphant defense" (I 828 / I 852 , 75 ). In other words, Whately identified presumptions as things to be presented as reasons supporting acceptance of conclusions in arguments to an audience.

Whately did not develop this point in detail, and his successors have not explored its implications. Even Gaskins, who acknowledges the rhetorical force of presumptions, devotes his energy to the antisociality implied by the burdenshifting effects of presumptions. But as Allen points out, we have other ways of describing the functions that presumptions, understood according to the common conception, perform within decisionmaking processes. There are, in contrast, no obvious substitutes for the term "presumption" in characterizing the reasons for a decision. This asymmetry suggests that the real significance of the term, and the most basic distinctiveness of presumptions, might lie not in their use as aids to deliberation, but in their characteristics as reasons.

\section{THE PUBLIC FACE OF PRESUMPTIONS}

Looking more carefully at what it might mean to view presumptions as reasons - at what is implied when we characterize a reason as a presumption - allows us to avoid 
some shortcomings of previous discussions of the topic by identifying defining features of presumptions other than their defeasibility and burden-shifting effects. Below, I first specify how presumptions function as reasons in the law, then explore some of the vocabulary available for analysis of the judicial practice of giving reasons, and finally explain, based on that vocabulary, what distinguishes presumptions from other reasons.

\section{a. Legal Reasons and Presumptions}

Reason-giving plays two distinct roles in the American legal system. The parties to a legal dispute present reasons for their positions in the form of evidence regarding historical facts and sets of legal inferences from them. These reasons are addressed to legal decisionmakers and are understood to provide the basis for resolution of the dispute. After some decisionmakers resolve disputes, however, they are also expected to provide reasons for those resolutions. These reasons are addressed to a wider audience - subsequent decisionmakers, litigants, and the public - and may include the reasons advanced by the parties but may also go beyond them.

Many explanations of this second form of reason-giving describe it as persuasive in its aim; it is widely held that courts give reasons for decisions at least in part to legitimate those decisions and, by implication, the decisionmakers' authority, since the judiciary lacks other indicia of legitimacy (Schauer 1995, 637, 653-4; Friedman 1992 , 91 8-9). While it is unclear whether judicial reason-giving actually secures public assent, this view of reason-giving remains intuitively plausible, particularly given the use made by judicial decisionmakers of their predecessors' reasons (Schauer 1991, 175-85). The practice of reliance on prior reasons allows judicial reason-giving to serve truth-oriented ends as well. Making reasons public allows the reasons-especially when they are generalizations - to be criticized, revised, and strengthened by subsequent reason-givers (Allen \& Pardo 2003, 1797; Goldman I999, I 39-44; Schauer I991, 39-43). In fact, since soliciting correction by specifying reasons can bolster the credibility of an arguer, the truth-oriented function of reason-giving is closely related to its legitimating purpose (Goldman I999, I09, I 42-9).

Most of the accounts discussed above address presumptions as reasons in the first sense-as reasons relied on by inquirers or decisionmakers, prior to the achievement of a final decision, as they seek to reach a correct result. The suggestion here is that we consider afresh how presumptions function as reasons in the second sense, when they are provided in support of an already achieved decision to justify a particular action. ${ }^{\mathrm{I}}$ Thinking about presumptions as reasons in this sense - as cited to secure support for an already achieved decision and to contribute to a longer-term approximation of truth-requires us to view them as fixed in a way foreign to the common conception. That conception sees presumptions as events occurring along the path to a conclusion and always at risk 
of disappearing if further information of the right kind comes along. But when, for example, a judge issues an order that cites the presumption of death after seven years' absence as one of the reasons for a directed verdict, the presumption becomes a permanent reason for that decision, not one that might subsequently disappear. ${ }^{2}$ As reasons, presumptions are not evanescent, as they seem to be when considered as rules for presentation of proof, although they are qualified in a different sense, explored below.

It is possible to be more specific about how presumptions function as reasons for an achieved decision. In a judicial opinion, references to presumptions as reasons can take two forms, one positive and one negative. In the positive form, a reason-giver states that a decision is based in part on the applicability of a presumption. An order granting a directed verdict in a custody dispute might grant custody to a relative based in part on the conclusion that another individual with a superior claim to custody is to be considered dead for purposes of the case, and explain this conclusion as in turn based on the parties' failure to present evidence of recent communications from the person together with the presumption triggered by the absence of such evidence. Both the absence of evidence and the presumptive rule, as well as the particular presumptive fact arising from their conjunction, are reasons for the decision. The reference to the presumption also involves an acknowledgment that the absence of evidence of a person's whereabouts is a circumstance that might not obtain in future cases, so that the same decision might not be reached in those cases. Still, the presumptions, in both senses, will always be reasons for this particular decision. The same implications are present in a case citing an interpretive presumption. When a presumption is cited as a reason in this way, it functions as a legal rule of sorts, but part of its significance is that - at least in theory - it might not ever apply again.

Presumptions can also be mentioned as reasons supporting a decision even though the ultimate conclusion is that they do not apply. In a case involving the extraterritorial application of a statute, a judge might decide that the statute does apply to extraterritorial conduct despite the presumption against extraterritorial application, but mention the presumptive rule anyway in the course of explaining the reasons for this decision. In such a case, the presumption forms one of the reasons for the decision, even though it is not accompanied by a presumed "fact"; it supplies the standard overcome by the considerations favoring application of the statute, which will also ordinarily be presented as reasons for the decision. In this context, the effect of mentioning the presumption is, again, to qualify the scope of the decision; mentioning the presumption warns that the decision at hand should not be generalized into a rule.

As I have just described them, presumptions seem to resemble other legal rules but to be less absolute than many other such rules. Superficially, this might seem to be just a different way of describing presumptions as defeasible. To move beyond this description, it is necessary to consider other features of the practice of reasongiving. 


\section{b. Some Features of Reason-Giving}

Although the practice of giving reasons is important both in and outside law, no standard vocabulary for analysis of the practice exists. Instead of trying to synthesize the disparate approaches to the topic, I will focus on one approach, Frederick Schauer's discussion of judicial reason-giving in a 1995 article, since it suggests a way of moving decisively beyond the common conception of presumptions.

Schauer makes two key points in this article. One is a point about the acts of generalization he considers to be inherent in the practice of reason-giving; the other is a point about the commitments implied by that practice. First, Schauer maintains that the practice of reason-giving is a special case of the practice of generalization. According to him, a reason must be "more general than the outcome it purports to justify"; otherwise, it does not "count as a reason" (635). His second point is that the practice of reason-giving by definition involves a form of commitment on the part of the reason-giver, since the effect of citing a generalization as a reason is to commit the person citing the generalization to application of the same generalization in future cases $(642-5)$. On closer analysis, the first of these points, concerning generalization, seems problematic and the second point more fundamental, although Schauer presents his point about commitment as derivative of his point about the generality of reasons.

The point about generalization is rendered problematic by experience and common usage. In law and in other forms of justification, factual propositions can and do often function as reasons alongside generalizations. Judicial opinions frequently cite evidence as well as norms among the reasons for particular outcomes. Indeed, rules could not provide support for an outcome if they were not related to the facts of the case. While Schauer acknowledges that judicial orders sometimes refer to factual findings, his definition of reason-giving excludes facts from the category of reasons without much explanation (637). ${ }^{3}$ In addition to being inconsistent with everyday practice, defining reasons as general rules presupposes a categorical distinction between factual issues and legal rules or norms that tends to fall apart under close examination (Allen \& Pardo 2003).

If facts can serve as reasons alongside rules, what does this imply for Schauer's point about commitment? Schauer links this point to his definition of reasons as generalizations: by pointing to a generalization as a reason for a decision, the reason-giver becomes committed to making a similar decision in future cases presenting sufficiently similar circumstances (642-5). Schauer offers several justifications, derived from this implied commitment, for the practice of reasongiving: because it involves commitment, reason-giving ensures legal stability, protects reliance interests, and can correct for bias resulting from a judge's attitude toward particular facts $\left(65_{3}\right)$. He also suggests a further implication of reasongiving, without linking it directly to his observations on commitment: the practice of giving reasons can be "a sign of respect" for the subject of the decision, "a way 


\section{Karen Petroski}

of opening a conversation rather than foreclosing one" (658). A decisionmaker who gives reasons acknowledges that the recipients of the decision are entitled to more than just the say-so of the decisionmaker, that they are to some extent entitled to draw their own conclusions about the acceptability of the decision and, perhaps, to criticize it (637). Really, this is simply another way of describing reason-giving as a tactic of legitimation. But in addition, by providing reasons, the decisionmaker actually enables the recipients of the decision to articulate and justify the independent conclusions they reach about the acceptability of the decision. In this way, a reason-giver commits him- or herself to a form of cooperation, and the reason-giver cannot completely escape the implications of this commitment, even if, as in Gaskins's account, the reasons provided are disingenuous. Further, this type of commitment is involved in the giving of any kind of reason, including both factual reasons and normative generalizations. In this sense, the commitment involved in reason-giving remains valuable even if not all reasons are generalizations, and even if some may be characterized as evasions of responsibility.

\section{c. What Types of Reasons Are Presumptions?}

What does all of this have to tell us about how presumptions function as reasons? In this section, I briefly discuss, first, how reasons characterized as presumptions display features associated with both factual and rule-like reasons, and then the forms of commitment this type of hybrid reason involves.

The description of a reason as a presumption, whether the presumption is cited as applying or as overcome, qualifies the conclusion and warns recipients that the decision and any generalizations apparently warranting it should not be used as reasons in subsequent decisions without additional analysis. Presumptions resemble factual reasons, then, in that describing a reason as a presumption carries no implied guarantee that the reason will ever function as a reason in any future case-such a description abjures the main forms of commitment analyzed by Schauer in his account of reasons-as-generalizations. At the same time, the traditional legal view of presumptions as more akin to legal rules than to facts is also justified. Like a more absolute rule, a presumptive rule provides a warrant for reaching one conclusion rather than another given a particular set of circumstances (and this is true of both rebuttable and irrebuttable presumptions). Presumptions are more than mere factual reasons; they connect facts to a conclusion and justify acceptance of this conclusion on the basis of these facts. In this sense, even though they are guaranteed to be good for one case only, presumptions resemble rules more than facts. ${ }^{4}$

The way in which presumptions combine features of factual reasons and rules also implies particular forms of commitment on the part of any person describing a reason as a presumption. Characterizing a reason as a presumption commits the reason-giver not just to the generalization implied by the presumption but 
also to a particular factual scenario. In standing behind the decision, the reasongiver stands behind the accuracy of a particular description of the world as constituted by the evidence in the case. Only under that description of the world does the presumption function as a reason. In this way, characterizing a reason as a presumption commits the reason-giver to more than does characterizing a reason as a rule. In addition, characterizing a reason as a presumption involves acknowledgment of the possibility that the reason will not apply in some or any future cases. This in turn makes each reference to a presumption into a reminder to subsequent decisionmakers of their own obligations to give reasons; subsequent decisionmakers cannot persuasively cite the presumption as a rule without explaining its relationship to the facts of their own cases. Characterizing a reason as a presumption thus acknowledges the contingency of reasons in a way that goes a step beyond the similar acknowledgment implied in every presentation of a rule as a reason (Schauer I 991, 35-6). When a reason is identified as a presumption, the reason-giver acknowledges not just the contingency of the decision's legitimacy on its acceptance by the decision's recipients, but also the fact that this legitimacy is contingent on the circumstances of the case, that other decisionmakers might reach other conclusions under other circumstances, and that all similarly situated decisionmakers are under an obligation to give reasons. ${ }^{5}$ No other type of reason commits a reason-giver to precisely this set of attitudes.

It is easy to think of any reference to a presumption as exhibiting a fear of commitment. But if my description is accurate, describing reasons as presumptions actually commits the reason-giver to both more and less than does describing reasons otherwise - as either rules or facts. The set of commitments involved-including commitment to the facts at hand, to the contingency of the decision both immediately and over the long term, and, above all, to the perpetuation of a practice of reason-giving - is communicated every time a reason is described as a presumption. Whether we view such a description as unusually honest or as an evasion of responsibility depends on considerations lying beyond the scope of this essay, such as the nature of the obligation to give reasons and the benefits and consequences of different approaches to reason-giving. Regardless of our evaluation of the practice, looking at presumptions in this light reveals that they play a distinct and valuable role, one that remains hidden as long as we take the common conception to be the only way of understanding them.

\section{REFERENCES}

Allen, Ronald J. I98 I. "Presumptions in Civil Actions Reconsidered." Iowa Law Review 66: 843-67.

Allen, Ronald J. \& Craig R. Callen. 2003. "The Juridical Management of Factual Uncertainty." International Journal of Evidence \& Proof 7: I-30.

Allen, Ronald J. \& Michael S. Pardo. 2003. "The Myth of the Law-Fact Distinction." Northwestern University Law Review 97(4): 1769-1807. 
American Banana Co v. United Fruit Co., 2 I 3 U.S. 347 (I 909).

Friedman, Richard D. I992. "Standards of Persuasion and the Distinction Between Fact and Law." Nortbwestern University Law Review 86(4): 916-42.

Gaskins, Richard H. 1992. Burdens of Proof in Modern Discourse. New Haven, CT: Yale University Press.

Goldman, Alvin I. 1999. Knowledge in a Social World. Oxford: Oxford University Press.

Hecht, Neil S. \& William M. Pinzler. 1978. "Rebutting Presumptions: Order out of Chaos." Boston University Law Review 58: 527-58.

Kaiser, David. I95 5. "Presumptions of Law and of Fact." Marquette Law Review 38: 253-6I.

Leibniz, Gottfried W. 1702/1887. "Letter to M. Jacquelot." In Philosophische Schriften, Vol. 3. C. I. Gerhardt (ed.). Berlin: Weidmannsche Buchhandlung.

McBaine, John P. 1938. "Presumptions: Are They Evidence?" California Law Review 26: 5I9-63.

Morgan, Edmund M. 1930. "Some Observations Concerning Presumptions." Harvard Law Review 44: 906-34.

Morgan, Edmund M. 1937. "Presumptions." Washington State Law Review \& State Bar Journal I 2: 255-8I.

Morgan, Edmund M. i95 5. "Presumptions." Rutgers Law Review io: 5 I 2-22.

Nance, Dale A. I 994. "Civility and the Burden of Proof." Harvard Journal of Law \& Public Policy I 7: 647-90.

Olshausen, George C. I 943 . "Evidence: Presumptions as Evidence-A Reply." California Law Review 3 I: 3 I6-25.

Rescher, Nicholas. 2006. Presumption and the Practices of Tentative Cognition. Cambridge: Cambridge University Press.

Schauer, Frederick. I991. Playing by the Rules: A Philosophical Examination of Rule-Based Decision-Making in Law and in Life. Oxford: Clarendon Press.

Schauer, Frederick. I 995. "Giving Reasons." Stanford Law Review 47: 633-59.

Thayer, James B. I 898. A Preliminary Treatise on Evidence at the Common Law. Boston: Little, Brown.

Walton, Douglas. 1996. Argumentation Schemes for Presumptive Reasoning. Mahwah, NJ: Laurence Erlbaum Associates.

Whately, Richard. I 828/i 85 2. Elements of Rhetoric. Boston: James Monroe \& Co.

\section{NOTES}

I The practice of offering reasoned decisions exists at least partly to justify particular judicial actions as well as the actions commanded by the court. In this light, the reasons given seem to be offered as reasons for action, not reasons for belief. But the function of reasons in judicial opinions blurs the distinction that philosophical analysis commonly draws between reasons for action and for belief. For one thing, the practice of giving reasons can be understood as motivated by a goal of truth approximation. In addition, as a legitimating tactic, reason-giving provides recipients with a basis for accepting a judicial action as a justified exercise of authority. This secondary action, if it occurs - the act of accepting authority - consists of a belief; acquiring the belief that the action was justified 
is identical with the act of conferring an important form of legitimacy on the action. I thank Walter Sinnott-Armstrong for encouraging clarification of this point.

2 Sometimes, a party will be able to reopen such a decision by pointing to new evidence, and in this case the reason characterized as a presumption would indeed disappear. But the legal system strongly discourages the revisiting of judgments and erects numerous obstacles to such a result. In most circumstances, the decision-and the reasons for it - will be fixed when the decision is announced. I thank Larry Laudan and Ron Allen for helping me to clarify this point.

3 This position seems to be in potential tension with the position taken by Schauer (I99I) in his work on the defeasibility of legal rules. There, Schauer argues that although we claim to use rules as if they were inflexible, most are in fact subject to defeat under certain circumstances $(35-6,196,203-4)$. Indeed, he suggests that many if not all rules should be understood as "presumptive," although he distinguishes his sense of this term from the sense used in evidence law (203). If the characterization presented in this essay is sound, the distinction might not be necessary. Presumptive rules, as reasons, are in fact just rules that are, to varying degrees, especially explicit about their defeasibility.

4 Because of their fact-sensitivity, presumptions might seem to resemble standards - rules' flexible cousins-more than rules. Yet presumptions differ from standards, too. Standards leave open the method by which a decision under the standard is to be reached (Friedman I992, 922-5, 94I). As persuasive devices, then, they may be suboptimal (Schauer I991, 77-8). Presumptions, in contrast, endorse and reflect a more structured process-dissected at length in accounts of the common conception - in which a decisionmaker has provisionally taken a general rule as given, then examined the context for specific defeating factors (Schauer i 991, 230). References to presumptions thus communicate a more systematic, less arbitrary relationship between reasons and conclusion than do references to standards, and greater sensitivity to particulars - perhaps conducing to greater accuracy - than do references to rules.

5 This acknowledgment is implied as well in references to irrebuttable and interpretive presumptions. Describing a reason as an irrebuttable presumption highlights its status as a legal fiction - a principle whose validity is contingent on cooperation.

Karen Petroski is an assistant professor at the Saint Louis University School of Law, where she teaches courses in procedure and statutory interpretation. She is currently working on projects examining the functions and implications of reason-giving in judicial opinions and the relationship between interpretive theory and practice. 